\title{
Influence of ecological role on bathymetric patterns of deep-sea species: size clines in parasitic gastropods
}

\author{
Craig R. McClain ${ }^{1,3, *}$, Jennifer Crouse ${ }^{2}$ \\ ${ }^{1}$ Department of Biology, University of New Mexico, Albuquerque, New Mexico 87131, USA \\ ${ }^{2}$ Department of Biology, University of Massachusetts, 100 Morrissey Blvd., Boston, Massachusetts 02125, USA \\ ${ }^{3}$ Present address: Monterey Bay Aquarium Research Institute (MBARI), 7700 Sandholdt Road, Moss Landing, \\ California 95039, USA
}

\begin{abstract}
How an organism's phenotype responds to both its biotic and abiotic environment is a complex interplay of selection pressures and adaptive tradeoffs. Bathymetric patterns of body size in deep-sea organisms should also reflect both ecological role and taxon-specific constraints, as exemplified in a variety of recent studies. Here, we examine bathymetric size clines in deep-sea ectoparasites, a group that has received little attention in the literature compared to other deep-sea groups. Specifically, we focus on body size in 3 families (21 species) of ptenoglossate gastropods from the deep western North Atlantic, conducting analyses both within and among species. Both quantile and linear regression models yielded non-significant relationships for body size and depth for the 3 most abundant species. Two of the 3 families exhibited positive size-depth relationships, but only in mean size. The findings indicate that resource availability/host size may control parasite density, but dislodgement and predation risk may set a hard upper boundary on body size in deep-sea ectoparasites. Moreover, this study stresses the necessity of understanding the ecological role of species in investigating body size trends.
\end{abstract}

KEY WORDS: Body size $\cdot$ Deep sea $\cdot$ Quantile regression $\cdot$ Ectoparasite $\cdot$ Gastropod $\cdot$ Western North Atlantic $\cdot$ Benthic $\cdot$ Parasitism

\section{INTRODUCTION}

Since the beginning of deep-sea exploration, authors have remarked on the miniaturization, and in some cases the gigantism, of deep-sea organisms (Mosely 1880). Subsequent research suggested that there may be no single pattern that characterizes bathymetric trends of body size among deep-sea species (reviewed in Rex \& Etter 1998, McClain et al. 2006). In the fauna as a whole, average size decreases with depth (Thiel 1975). Within phylogenetic clades, patterns are determined by a variety of interacting, and often opposing, forces (McClain et al. 2005). Because body size is an outcome of genetic and/or plastic responses to the selection affecting development, physiology, behavior, ecology, and life-history traits (Smith \& Lyons 2006), perhaps it is not unexpected that an assortment of patterns is reported. For example, meiofauna may exhibit no or only weak size-depth patterns due to constraints of different sediment types (Schwinghamer 1981, 1985, Stoetaert \& Heip 1989, 2002). Some groups may be more sensitive to variation in abiotic variables such as oxygen (Chapelle \& Peck 1999, 2004, McClain \& Rex 2001, Peck \& Chapelle 2003). If spatio-temporal variation in carbon flux drives patterns of body size, then different feeding types are expected to exhibit differential responses (Collins et al. 2005).

Previous studies on body size patterns in the deep sea encompass a variety of taxa with different feeding types and life histories (Rex \& Etter 1998). Noticeably 
absent is research on size clines in parasitic species, despite numerous studies exploring the implications of parasitism, primarily obligate endoparasites, for body size in other environments (Poulin 1995b and references within). This work has demonstrated that the evolution of body size in parasites does adhere to a single exact rule. Multiple outcomes are possible depending on the path of transition to parasitism. Clearly, a parasitic lifestyle imposes a series of size constraints on species enabling exploitation of the host habitat. Traditionally reduced size has been thought to confer the advantage of allowing exploitation of a greater variety of hosts or infection sites (Price 1980, Hanken \& Wake 1993). However, increases in size are seen in parasites of vertebrates compared to those of invertebrates (Kirchner et al. 1980). For copepods, changes in size may also accompany evolutionary switches between free-living lifestyle, invertebrate parasitism, and vertebrate parasitism (Poulin 1995a). For isopods, decreases in size during the evolution of parasitism occur (Poulin 1995b). Host size is positively correlated with parasite size in isopods (Poulin 1995b and references within),

Table 1. Taxonomic placement of the group 'Ptenoglossa'

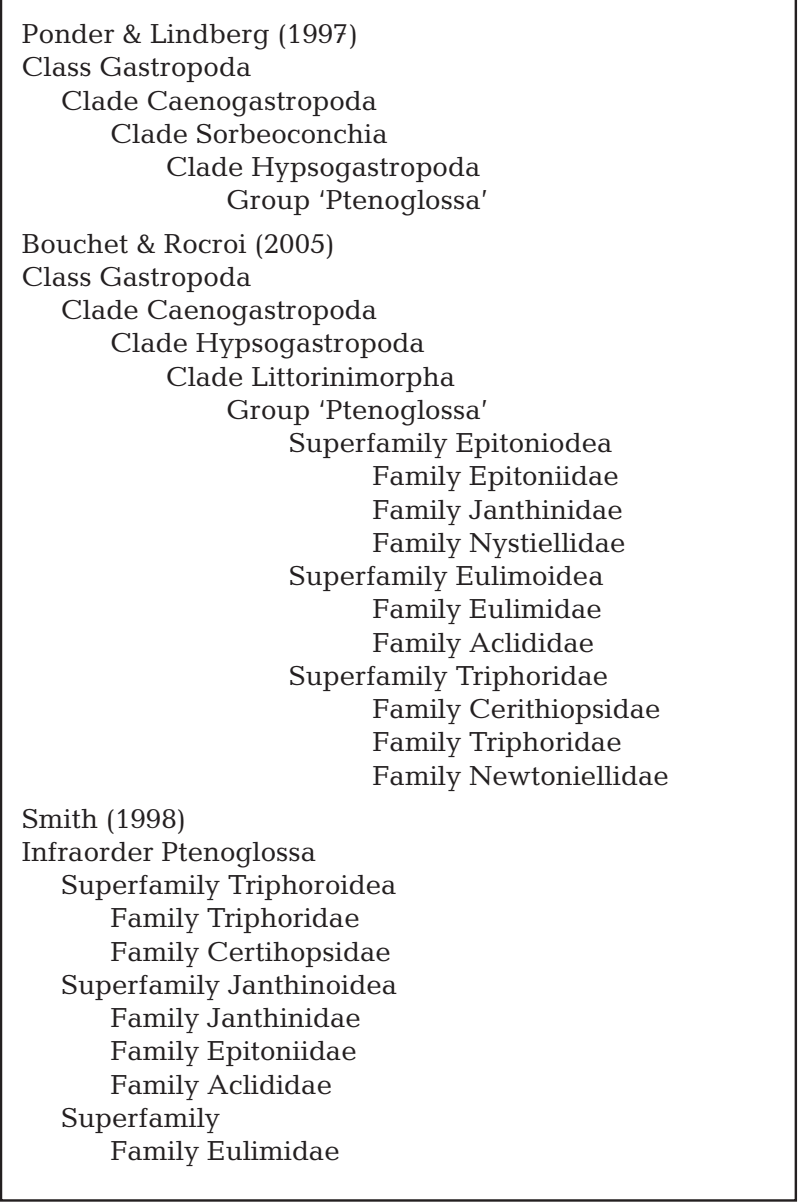

but not in copepods or monogeans (Poulin 1996). Differences in size are also seen between endoparasites and ectoparasites, with ectoparasite size constrained by increased likelihood of dislodgement (Poulin \& Morand 1997).

We focused on 3 families of ptenoglossate gastropods in the deep western North Atlantic: Aclididae, Eulimidae, and Epitoniidae. The group Ptenoglossa is likely a paraphyletic or polyphyletic group (Ponder \& Lindberg 1997), established originally of unspecified rank by Gray (1853). It is generally agreed upon that the group is above the level of family and generally is defined as a suborder (Bouchet \& Rocroi 2005), although classifications such as infraorder (Smith 1998) have also been made. Certain is that all 3 of these families are included in the clade Caenogastropoda (Bouchet \& Rocroi 2005), which consists of all those 'taxa ... sharing a more recent common ancestor with Conus (and Murex) than with Tonna' (Ponder \& Lindberg 1997, p. 225). The Caenogastropoda may also be distinguished by the presence of a second muscle cell type in the columellar/shell muscle that does not appear to be present in vetigastropods and heterobranchs (Ponder \& Lindberg 1997). Most ptenoglossates possess acrombolic proboscides and radulae distinctive to the group (Ponder \& Lindberg 1997). Differences exist in the classification of these gastropod families (Table 1) into superfamilies and into the Ptenoglossa. Bouchet \& Warén (1986) include the eulimids in the Ptenoglossa; however, in a subsequent evaluation by Ponder \& Warén (1988) this placement is questioned. Bouchet \& Rocroi (2005) classify Eulimidae and Aclididae as sister families, while Smith (1998) places Epitoniidae and Aclididae as sister groups (Table 1). To date, no species level phylogenies exist for any of these families. It is not our intention to resolve this classification issue, but rather to examine size-depth patterns in these organisms as a group based on a similar life style.

This gastropod group is known to be generally ectoparasitic and exhibits a range of parasitism and specialization. Most eulimids are highly specialized and exclusively ectoparasitic on echinoderms that are permanently attached to a single host (Smith 1998), although some species may transfer between hosts repeatedly during their lifespan (A. Warén pers. comm.). A few species, not included in this study, have undergone numerous morphological adaptations, including anatomical reductions, to exploit hosts as endoparasites (Smith 1998). Shell morphology can be extremely variable, reflecting specialization for parasitism, with males typically smaller than females (Smith 1998). Epitoniids are generally considered to be ectoparasites, although some authors have defined this group by various degrees of commensalism and preda- 
tion (Smith 1998). In contrast to eulimids, epitoniids are exclusively ectoparasitic on cnidarians, primarily anemones and corals, and reside in the sediment near their hosts (Smith 1998). A modified radula and jaw are used to bite pieces of their hosts (Smith 1998). The host specificity of aclids is less clear, and this group appears to be more facultative and less specialized (Bouchet \& Warén 1986).

All 3 of these families are distinct from their deepsea caenogastropod relatives, which are scavengers and predators (McClain et al. 2005) and thus likely to experience different body size constraints. Here, we utilize this unique set of deep-sea ptenoglossate gastropods to examine the importance of ecological role, as well as taxon-specific constraints, on bathymetric size patterns both among and within species.

\section{MATERIALS AND METHODS}

The ptenoglossates were collected from 16 sampling stations along the Gayhead-Bermuda Transect (GBT) in the western North Atlantic, covering a latitudinal range of 65.9 to $71.1^{\circ} \mathrm{N}$ and a longitudinal range of 36.4 to $40.0^{\circ} \mathrm{W}$. The samples were collected by the Woods Hole Benthic Sampling Program, and were taken from depths of 196 to $4825 \mathrm{~m}$ using anchor dredges and epibenthic sleds (Sanders 1977). The data presented here represent 291 individuals distributed among 21 species.

Shell measurements were obtained by using a Nikon SMZ1000 dissection microscope mounted with a Spot RT digital camera. The shell was placed on a clay disk mounted on a Zeiss 4-axis universal stage and was oriented such that both the plane of the aperture and the axis of coiling were parallel to the base of the microscope. The image of the shell in this orientation was imported into a Macintosh G4 using Spot Advanced software. Body size was measured as the sum of the length and width (Rex \& Etter 1998, Rex et al. 1999, Clain \& Rex 2000, McClain \& Rex 2001, McClain et al. 2005). Of course, size can measured in a variety of ways that may affect the observed patterns. Other size metrics, length, width, and volume were also explored and yielded similar patterns to those given here. Here, we report only the sum of the length and width so that results are comparable to those reported before for deep-sea gastropods. To explore bathymetric size gradients, we used ordinary least squares regression (OLS). To separate patterns in body size from patterns in population struc- ture, we utilized quantile regression. Previous research has documented the sensitivity of standard regression techniques to localized recruitment events and the age structure of the local populations (McClain \& Rex 2001). Quantile regression has been shown to be effective in documenting size patterns (McClain \& Rex 2001, Roy et al. 2003, McClain et al. 2005) and allows us to specifically examine how only maximum size is limited over depth. A previous study has shown that bathymetric relationships of size are unimodal, with body size increasing to $4000 \mathrm{~m}$ and then sharply decreasing (McClain et al. 2005).

Here, we use only linear models to test for trends, because all the species occur below this $4000 \mathrm{~m}$ threshold. No within-family phylogeny exists for any of these groups, and, as indicated above, even the placement of families is questionable. Given the lack of an accurate phylogeny, we do not control for its effect in the analyses. Recent work suggests that inaccurate phylogenies can lead to poor performance of phylogenetic correction methods and can, in specific cases, increase the non-independence in the dataset (Abouheif 1999). Analyses were performed for the families Aclididae, Eulimidae, and Epitoniidae and the 3 most abundant species (Aclis walleri, Melanella species 1, and Haliella stenostoma), with critical alpha values for significance determined by Bonferroni correction. Intraspecific analyses were not conducted for other species because of either inadequate depth coverage (species was collected at $\leq 2$ stations) or small sample sizes.

\section{RESULTS AND DISCUSSION}

The majority of the analyses for the 3 individual species (Aclis walleri, Melanella species 1, and Haliella stenostoma) show no significant size pattern for size with depth (Tables $2 \& 3$, Fig. 1). The only significant regression is the OLS for $A$. walleri, which is not

Table 2. Ptenoglossate gastropods. Ordinary least squares linear regression results for families and the 3 most abundant species. Significant values, determined by Bonferroni correction (24 independent tests, critical alpha $=0.0021$ ) are in bold; significant regression lines shown in Figs. 1 \& 2; $y$ is size as length + width and $x$ is depth

\begin{tabular}{|cccrc|}
\hline & $\mathrm{N}$ & Equation & $\mathrm{p}$-value & $\mathrm{r}^{2}$ \\
\hline Species & & & & \\
$\quad$ Aclis walleri & 121 & $\mathrm{y}=\mathbf{2 . 7 1 + \mathbf { 0 . 0 0 1 1 }}$ & $<\mathbf{0 . 0 0 1 0}$ & $\mathbf{0 . 2 4 5 0}$ \\
Melanella species 1 & 46 & $y=2.52+0.0082 \mathrm{x}$ & 0.1815 & 0.0400 \\
Haliella stenostoma & 25 & $y=3.17+0.0011 \mathrm{x}$ & 0.1304 & 0.0970 \\
Family & & & & \\
Aclididae & 127 & $\mathrm{y}=\mathbf{2 . 6 6 + \mathbf { 0 . 0 0 1 1 }}$ & $<\mathbf{0 . 0 0 0 1}$ & $\mathbf{0 . 2 5 7 0}$ \\
Eulimidae & 141 & $\mathrm{y}=\mathbf{2 . 3 6 + \mathbf { 0 . 0 0 0 5 x }}$ & $<\mathbf{0 . 0 0 0 1}$ & $\mathbf{0 . 4 1 1 0}$ \\
Epitoniidae & 23 & $y=7.91-0.0013 x$ & 0.4581 & 0.0265 \\
& & & & \\
\hline
\end{tabular}


Table 3. Ptenoglossate gastropods. Quantile regression results for families and the 3 most abundant species. Note that none of the quantile regressions were significant, $y$ is size as length + width and $x$ is depth

\begin{tabular}{|c|c|c|c|c|c|c|c|c|c|c|}
\hline & $\mathrm{N}$ & Equation & $\mathrm{p}$-value & R1 & Equation & $\mathrm{p}$-value & R1 & Equation & $\mathrm{p}$-value & R1 \\
\hline \multicolumn{11}{|l|}{ Species } \\
\hline Aclis walleri & 121 & $y=7.68-0.0008 x$ & 0.3500 & 0.0964 & $y=6.07-0.0001 x$ & 0.8192 & 0.9067 & $y=5.24+0.0003 x$ & 0.1648 & 0.0248 \\
\hline Melanella species 1 & 46 & $y=4.73-0.0004 x$ & 0.9224 & 0.0272 & $y=3.94+0.0002 x$ & 0.7454 & 0.0168 & $y=3.51+0.0005 x$ & 0.3158 & 0.0220 \\
\hline Haliella stenostoma & 25 & $y=9.84-0.0009 x$ & 0.8092 & 0.1015 & $y=9.84-0.0009 x$ & 0.8440 & 0.0495 & $y=6.62+0.0004 x$ & 0.6764 & 0.0201 \\
\hline \multicolumn{11}{|l|}{ Family } \\
\hline Eulimidae & 141 & $y=10.00+0.0002 x$ & 0.6202 & 0.0427 & $y=7.53+0.0001 x$ & 0.5326 & 0.0110 & $y=4.62+0.0010 x$ & 0.1402 & 0.0444 \\
\hline Epitoniidae & 23 & $y=10.33+0.0034 x$ & 0.7522 & 0.1249 & $y=10.33+0.0034 x$ & 0.7692 & 0.0317 & $y=12.92-0.0017 x$ & 0.4256 & 0.0671 \\
\hline
\end{tabular}

repeated in the quantile regression results. Overall, the evidence for bathymetric size trends in individual ectoparasitic species is unsubstantial. For Aclididae, the significant OLS regression is driven by A. walleri, which comprises a majority of the individuals in the within-family analysis (Tables 2 \& 3, Fig. 2). For Eulimidae, depth and body size are positively related in the OLS regression, despite the 2 most abundance species of the family, Melanella species 1 and $H$. stenostoma, displaying non-significant regressions (Tables $2 \& 3$, Fig. 2). Despite the relationship for mean size in the OLS analyses, these same 2 families exhibit no overall pattern in maximum size (Tables $2 \& 3$, Fig. 2). The third family, Epitoniidae, exhibits no pattern over depth in mean or maximum size, which may relate to the poor bathymetric coverage and low sample size.

The results are in contrast to previous findings for western North Atlantic deep-sea gastropods, for which prominent bathymetric patterns exist both at the species level and at higher phylogenetic levels (Rex \& Etter 1998, Rex et al. 1999, Clain \& Rex 2000, McClain \& Rex 2001, McClain et al. 2005). Overall, the pattern in deep-sea gastropods is unimodal, with body size increasing up to $4000 \mathrm{~m}$ and then sharply decreasing. The increases in size with depth seen among other gastropod species have been attributed to the selection pressure from diminishing food resources with depth (Rex \& Etter 1998, Rex et al. 1999, McClain et al. 2005). Larger body sizes confer greater metabolic efficiency, enhanced competitive ability, exploitation of a broader range of food items, less susceptibility to starvation, and increased foraging area (McClain et al. 2005). However, when food availability reaches a critical lower threshold, large sizes and minimum viable population sizes cannot both be maintained and the community structure, including the body size distribution, may be driven by source-sink dynamics (Rex et al. 2005). Yet, unlike their gastropod relatives, ectoparasitic gastropods may experience variation in carbon flux only indirectly through their hosts.
For only 1 family, Euliimidae, is the host group and its bathymetric size patterns known. Many different body size patterns have been reported for their echinoderm hosts, from: (1) positive (Fujita \& Ohta 1990), (2) negative (Gage \& Tyler 1982), to (3) no bathymetric pattern (Polloni et al. 1979). The study by Polloni et al. (1979) was the only study on echinoderms in the western North Atlantic. Although they reported that there was no bathymetric pattern, the data appear to support a unimodal pattern. Previous hypotheses for bathymetric size clines were centered on linear patterns; thus, authors, including us, typically implemented standard linear statistical techniques. Only recently has it been recognized that the relationship may be unimodal (McClain et al. 2005). The data from Polloni et al. (1979) were fitted with linear OLS, but the data actually exhibit an increase in maximum size with depth until the lower continental rise, where maximum size quickly diminishes. This unimodal pattern is very similar to that reported for gastropods along the same transect (McClain et al. 2005).

Tsai et al. (2001) demonstrated that host body size dictates the total parasite biomass possessed by the host. Yet a given biomass can produce a number of density and size distribution relationships (Allen et al. 2002). Thus, increases in host body size, i.e. greater resource availability, can lead to either a greater parasite load (Poulin \& Rohde 1997, Poulin 1999, Poulin \& Valtonen 2001, George-Nascimento et al. 2004) or larger parasite body sizes (Morand et al. 1996, Poulin 1996, Tsai et al. 2001), or various combinations of the 2 alternatives. Interestingly, the euliimids display no pattern in size despite the increased size over depth in echinoderms, suggesting increased resource availability manifests itself in greater parasite density. Indeed, the significant trends in mean size for Aclidae and Eulimidae, but not in maximum size, imply that it is density in the form of increased recruitment and not body size that is reacting to changes in productivity over depth. Data are presently unavailable to test 
these hypotheses explicitly; however, this area provides a promising line for future research.

Within species, the lack of size clines may suggest changes of parasite load with depth. Conversely, ectoparasite body size may not be related to resource
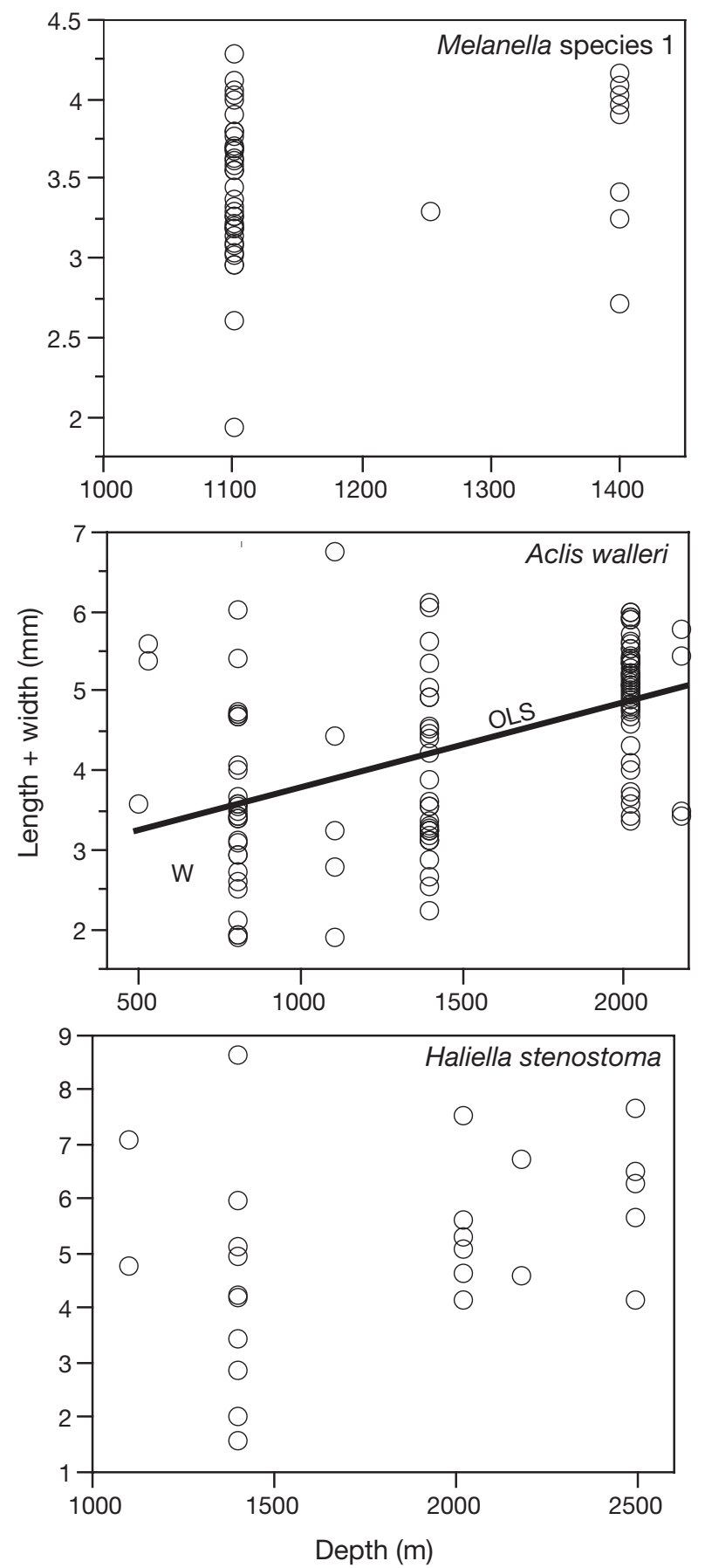

Fig. 1. Ptenoglossate gastropods. Relationship between size (length + width) and depth for the 3 most abundant species. A significant regression line is shown in the figure (OLS: ordinary least squares regression). Regression statistics and equations can be found in Tables 1 \& 2 availability/host size, but rather to external factors (Poulin 1996). For example, the lack of patterns seen in the epitoniids may indicate constraints on shell form and size experienced by burrowing gastropods (Vermeij 1993). For ectoparasites permanently attached to
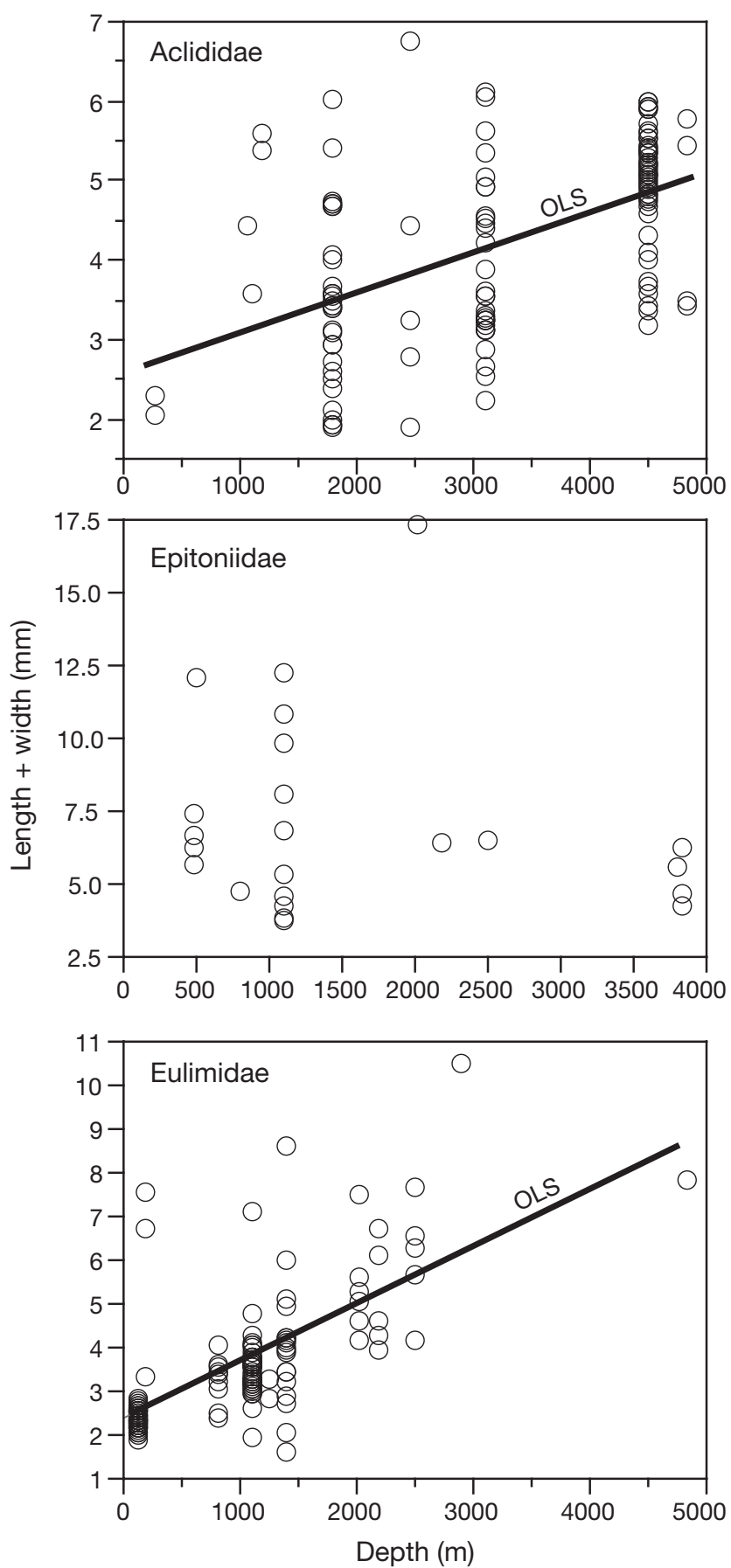

Fig. 2. Ptenoglossate gastropods. Relationship between size (length + width) and depth at the family level. Significant regression lines are shown in the figures (OLS: ordinary least squares regression). Regression statistics and equations can be found in Tables 3 \& 4 
their hosts, size can represent a tradeoff between selection pressure for increases in size for greater reproductive output and decreases in size to decrease dislodgement risk (Poulin \& Morand 1997). Indeed, host detachment poses a severe threat when host populations experience densities as low as those found in the deep sea. One of the many adaptations to decrease dislodgement, is the production of a high-spired shell, which greatly reduces lift (Vermeij 1993). All of the species analyzed here are of this form, with heights greatly exceeding widths. In addition, another very effective measure is a reduction in size, thereby reducing drag, lift, and acceleration reaction (Vermeij 1993). The ptenoglossates reported here are significantly smaller than other caenogastropod species (McClain et al. 2005) in the same set of samples (unequal variances $t$-test: $\mathrm{N}=98, \mathrm{df}=87.03, \bar{x}_{\text {ptenoglossata }}=2.60, \bar{x}_{\text {other }}=4.50$, $\mathrm{p}=0.0196)$.

Intuitively, it may seem that dislodgement stress is a relatively unimportant factor for individuals inhabiting echinoderms in a low current regime like the deep sea. Yet, the notion of the deep sea as a relatively stable environment has been overturned by a multitude of research efforts demonstrating that areas of the seafloor are subject to strong flows and episodic benthic storms (Levin et al. 2001). Moreover, the increased density of water due to lower temperatures, increased pressure, and the effects of the benthic boundary layer can also increase drag and accelerational force (Denny 1999). Alternatively, A. Warén (pers. comm.) has found that size in ptenoglossates is related to the ability of the host to provide protection from predation. In the genus Pelseneeria, larger species are found on urchins with longer spines (A. Warén pers. comm.). In Melanella, larger species are found on burrowing holothurians, as opposed to surfaced dwellers (A. Warén pers. comm.).

The research here thus points to host size potentially limiting the density of individual parasitic species, but external factors, such as dislodgement risk or predation, controlling ectoparasite body size. At the family level, positive bathymetric patterns in mean body size may reflect either changes in actual body size or greater recruitment in response to changes in resource supply, i.e. host body size. This study adds to the growing body of literature indicating that bathymetric size clines are influenced by the varying ecological roles species play within deep-sea communities. To confound these patterns further, linear changes in environmental factors may illicit unimodal responses in body size (McClain et al. 2005), and there are multiple abiotic/biotic correlates with depth. The study concentrates on only 1 transect and taxon, and, thus, the generality of these patterns needs to be addressed with further work in different regions and groups. The present study underscores the value of appropriate statis- tical analysis, consideration of the ecological role species play, and exploring size relationships at multiple phylogenetic levels, for comprehending body size gradients in the deep sea.

Acknowledgements. We thank J. Nekola, R. Poulin, M. Rex, A. Warén, and P. Bouchet for providing constructive commentary on the manuscript. Two anonymous reviewers also provided valuable comments. This research was funded by ORS0000010870 to J. Brown and B. Milne and GER-9552836 and OCE-0135949 to M. Rex.

\section{LITERATURE CITED}

Abouheif E (1999) A method for testing the assumption of phylogenetic independence in comparative data. Evol Ecol Res 1:895-909

Allen AP, Brown JH, Gillooly JF (2002) Global biodiversity, biochemical kinetics, and the energetic-equivalence rule. Science 297:1545-1548

Bouchet P, Rocroi JP (2005) Classification and nomenclator of gastropod familes. Malacologia 47:1-397

Bouchet P, Warén A (1986) Revision of the northeast Atlantic bathyal and abyssal Aclididae, Eulimidae, Epitoniidae (Mollusca, Gastropoda). Boll Malacol (Suppl)2:288-576

Chapelle G, Peck LS (1999) Polar gigantism dictated by oxygen availability. Nature 399:114-115

Chapelle G, Peck LS (2004) Amphipod crustacean size spectra: new insights in the relationship between size and oxygen. Oikos 106:167-175

Clain AJ, Rex MA (2000) Size-depth patterns in two bathyal turrid gastropods: Benthomangelia antonia (Dall) and Oenopota ovalis (Friele). Nautilus 114:93-98

Collins MA, Bailey DM, Ruxton GD, Priede IG (2005) Trends in body size across an environmental gradient: a differential response in scavenging and non-scavenging demersal deep-sea fish. Proc R Soc B 272:2051-2057

Denny MW (1999) Are there mechanical limits to size in wave-swept organisms? J Exp Biol 202:3463-3467

Fujita T, Ohta S (1990) Size structure of dense populations of the brittle star Ophiura sarsii (Ophiuroidea: Echinodermata) in the bathyal zone around Japan. Mar Ecol Prog Ser 64:113-122

Gage JD, Tyler PA (1982) Depth-related gradients in size structure and the bathymetric zonation of deep-sea brittle stars. Mar Biol 71:299-308

George-Nascimento M, Munoz G, Marquet PA, Poulin R (2004) Testing the energetic equivalence rule with helminth endoparasites of vertebrates. Ecol Lett 7: $527-531$

Gray JE (1853) On the division of ctenobranchous gasteropodous Mollusca in larger groups and families. Ann Mag Nat Hist II 11:124-132

Hanken J, Wake DB (1993) Miniaturization of body size: organismal consequences and evolutionary significance. Annu Rev Ecol Syst 24:501-519

Kirchner TB, Anderson RV, Ingham R (1980) Natural selection and the distribution of nematode sizes. Ecology 61: 232-237

Levin LA, Etter RJ, Rex MA, Gooday AJ, Smith CR, Pineda J, Stuart CT (2001) Environmental influences on regional deep-sea species diversity. Annu Rev Ecol Syst 32:51-93

McClain CR, Rex MA (2001) The relationship between dissolved oxygen concentration and maximum size in deep- 
sea turrid gastropods: an application of quantile regression. Mar Biol 139:681-685

McClain CR, Rex MA, Jabbour R (2005) Deconstructing bathymetric patterns of body size in deep-sea gastropods. Mar Ecol Prog Ser 297:181-187

McClain CR, Rex MA, Etter RJ (2006) Deep-sea macroecology. In: Witman JD, Roy K (eds) Marine macroecology. University of Chicago Press, Chicago

Morand S, Legendre P, Gardner SL, Hugot JP (1996) Body size evolution of oxyurid (Nematoda) parasites: the role of hosts. Oecologia 107:274-282

Mosely HN (1880) Deep-sea dredging and life in the deep sea. III. Nature 21:591-593

Peck LS, Chapelle G (2003) Reduced oxygen at high altitude limits maximum size. Proc R Soc B 270:166-167

Polloni P, Haedrich R, Rowe GT, Clifford CH (1979) The sizedepth relationship in deep ocean animals. Int Rev Gesamten Hydrobiol 64:39-64

Ponder WF, Lindberg DR (1997) Towards a phylogeny of gastropod molluscs: an analysis using morphological characters. Zool J Linn Soc 119:83-265

Ponder WF, Warén A (1988) Classification of the Caenogastropoda and Heterostropha - a list of the family-group and higher category names. In: Ponder WF (ed) Prosobranch phylogeny. Malacol Rev (Suppl 4):288-326

Poulin R (1995a) Clutch size and egg size in free-living and parasitic copepods - a comparative analysis. Evolution 49:325-336

Poulin R (1995b) Evolutionary influences on body size in freeliving and parasitic isopods. Biol J Linn Soc 54:231-244

Poulin R (1996) The evolution of body size in the Mongenea: the role of host size and latitude. Can J Zool 74:726-736

Poulin R (1999) Body size vs. abundance among parasite species: positive relationship. Ecography 22:246-250

Poulin R, Morand S (1997) Parasite body size distributions: interpreting patterns and skewness. Int $\mathrm{J}$ Parasitol 27: 959-964

Poulin R, Rohde K (1997) Comparing the richness of metazoan ectoparasite communities of marine fishes: controlling for phylogeny. Oecologia 110:278-283

Poulin R, Valtonen ET (2001) Interspecific associations among larval helminths in fish. Int J Parasitol 31:1589-1596

Price PW (1980) Evolutionary biology of parasites. Princeton University Press, Princeton, NJ

Rex MA, Etter RJ (1998) Bathymetric patterns of body size: implications for deep-sea biodiversity. Deep-Sea Res II 45: 103-127

Editorial responsibility: Otto Kinne (Editor-in-Chief), Oldendorf/Luhe, Germany
Rex MA, Etter RJ, Clain AJ, Hill MS (1999) Bathymetric patterns of body size in deep-sea gastropods. Evolution 53: 1298-1301

Rex MA, McClain CR, Johnson NA, Etter RJ, Allen JA, Bouchet P, Warén A (2005) A source-sink hypothesis for abyssal biodiversity. Am Nat 165:163-178

Roy K, Collins AG, Becker BJ, Begovic E, Engle JM (2003) Anthropogenic impacts and historical decline in body size of rocky intertidal gastropods in southern California. Ecol Lett 6:205-211

Sanders HL (1977) Evolutionary ecology of the deep-sea benthos. In: The changing scenes in natural sciences: 1776-1976. Spec publ, Academy of Natural Sciences, Philadelphia

Schwinghamer P (1981) Characteristic size distributions of integral benthic communities. Can J Fish Aquat Sci 38: 1255-1263

Schwinghamer P (1985) Observation on size-structure and pelagic coupling of some shell and abyssal benthic communities. Eur Symp Mar Biol 19:347-359

Smith BJ (1998) Superfamily Janthinoidea and Eulimoidea. In: Beesley PL, Ross GJB, Wells A (eds) Mollusca: the southern synthesis, Part B, Vol 5. Australian Biological Reserve, Canberra, p 811-817

Smith FA, Lyons K (eds) (2006) Body size: linking pattern and process across space, time and taxonomic group. University of Chicago Press, Chicago, IL

Stoetaert K, Heip C (1989) The size structure of nematode assemblages along a Mediterranean deep-sea transect. Deep-Sea Res 36:93-102

Stoetaert K, Heip C (2002) Size and shape of ocean margin nematodes: morphological diversity and depth-related patterns. Mar Ecol Prog Ser 242:179-193

Thiel H (1975) The size structure of the deep-sea benthos. Int Rev Gesamten Hydrobiol 60:575-606

Timofeev SF (2001) Bergmann's principle and deep-water gigantism in marine crustaceans. Biol Bull (Woods Hole) 28:646-650

Tsai ML, Li JJ, Dai CF (2001) How host size may constrain the evolution of parasite body size and clutch size. The parasitic isopod Icthyoxenus fuhanensis and its host fish, Varicorhinus bacbatulus, as an example. Oikos 92:13-19

Vermeij GJ (1993) A natural history of shells. Princeton University Press, Princeton, NJ

Warén A, Bouchet P (1986) Revision of the Northeast Atlantic ptenoglossate Meosgastropoda. Boll Malacol (Suppl)2: $297-576$

Submitted: July 12, 2005; Accepted: February 7, 2006

Proofs received from author(s): August 2, 2006 